\title{
Incidental News: How Young People Consume News on Social Media
}

\begin{abstract}
This paper examines the dynamics of news consumption on social media through sixteen openended interviews with young users from Argentina. It adopts a texto-material perspective to explore the role of technology and users' motivations, actions and interpretations. The interviews reveal that the idealtypical mode in which young users consume news on social media can be characterized with the notion of "incidental news": most young users get the news on their mobile devices as part of their constant connection to media platforms; they encounter the news all the time, rather than looking for it; but click on them only sporadically and spend little time engaging with the content. Thus, the news becomes undifferentiated from the rest of the social and entertainment information. This mode of news access marks a significant discontinuity with the consumption of news on other media. It also raises major editorial and political implications.
\end{abstract}

\section{Introduction}

The consumption of news is essential to participation in social, cultural and political life [18], [19], [31], [37], [50]. During the second half of the twentieth century there was a fairly stable regime of news consumption practices across the dominant media of the time - print, radio and television. The advent of the all-news, 24-hour cable television in the 1980s began to destabilize this regime, and the commercialization of the web in the mid-1990s altered it dramatically. This triggered a flurry of research about the dynamics of online news consumption-for a review of this scholarship, see [36]. In the past few years the emergence and rapid popularization of social media has further upended the status quo of news consumption. According to a recent Pew report, 62\% of the adult population in the United States gets news on social media [24]. Despite the popularity of news consumption in social media, little is known about its dynamics, the role of technology, and the similarities and differences with respect to print, broadcast, and web options.
This paper contributes to fill this void through an exploratory study of how young users consume news on social media. It is based on sixteen open-ended interviews with people ages 18 to 29. The interviews were undertaken in Argentina, between March and June, 2016. Open-ended interviews are well suited for exploratory research because they enable the analyst to let interviewees describe the practices and meanings associated with new technical capabilities - in this case, the use of social media for news consumptionin whichever way they deem suitable and without parameters of inquiry imposed beforehand, as in the case of surveys or experiments. The focus on young users is because when it comes to social media they have often functioned as "lead sources of innovation" [52] by developing modes of interaction that they get later adopted by other age groups. Moreover, news consumption lifetime habits are often set by the time individuals turn 30 years of age [16], [2]. The choice to locate the research in Argentina is to offer an alternative to the U.S.-centered geographic focus of the vast majority of studies of technological and cultural practices in social media.

Because the consumption of news on social media-or any other device — is both a technological and a content practice, we adopt a "texto-material perspective" [44] to analyze our data. This perspective stems from the notion that media technologies are unique types of artifact in that they are "at once cultural material and material culture" [6, p. 955]. Thus, to make sense of this duality a texto-material perspective looks at issues of technological infrastructures and actions; content configurations; and the agency of users in weaving technology and content in their everyday practices.

We find that the ideal-typical mode in which young users consume news on social media can be characterized with the notion of "incidental news". Most young users get the news on their mobile devices as part on being on platforms like Facebook or Twitter. They encounter the news, rather than looking for it. They do this as part of living in the media, rather using media. The affordances of mobile devices enable constant connectivity, and the algorithmic logic of Facebook and the chronological logic of Twitter undifferentiates news content from other forms of content that they encounter on their social media feeds. Young 
users encounter news on social media all the time, but click on them only sporadically--and once they do they spend little time reading or viewing the content. News consumption is integrated into broader patterns of social media sociability, but at the expense of understanding the news report as a unique entity that deserves special attention and has an integrity of its own - the notion that a newspaper or a television show is an authoritative rendition of the day's main events loses significance in the social media maelstrom. Thus, the emergence of incidental news marks a significant discontinuity with the consumption of news in print and broadcast media, and, albeit to a lesser extent, with the consumption of news on the web using computers. There was incidental learning of news in print and broadcast media, as has been argued by a number of scholars, and it increased with the advent of the internet [18], [30], [49]. But it was secondary to the more purposeful consumption of news. By contrast, what we describe in this paper as "incidental news" is the predominant mode of information acquisition among young consumers. This, in turn, raises major editorial and political implications that we explore in the last section of this paper.

\section{Related work}

\subsection{News consumption in print and broadcast media ${ }^{1}$}

There has been a long tradition of scholarship on the social and cultural character of news consumption in print and broadcast media. Three consistent findings are relevant for this study. They are that news consumption in these media re highly routinized; structured along predictable temporal and spatial dimensions; and that they are integrated into the relational patterns of daily life.

The habitualization of news consumption manifests itself in at least two interrelated ways: the interpenetration of the practices whereby people get the news with those that pertain to other domains of daily life, and the adoption of specific routines to organize these practices. For instance, Gauntlett and Hill [21] argued that sometimes people select channels and shows less based on ideological affinity or quality and more on their own temporal availability given whatever else was going on in their day. Lull [33] adds

\footnotetext{
${ }^{1}$ This research compares news consumption through social media to news consumption on broadcast and print media. Consumption of other types of content, such as fiction or entertainment, is organized differently in both legacy and new media.
}

that in the home setting, viewing routines emerge relatively rapidly within the television season and get reproduced without much explicit discussion. Finally, Bogart [9] notes that newspaper reading practices are also habitualized, with many readers starting with the front page and systematically going through the rest.

Studies of news consumption in print and broadcast media have also underscored the organization of this activity along spatial and temporal coordinates. The default space of news consumption in these media has been the home, in particular for television [14], [32], [38], [45]. Webster and Phalen [53] note that this shows up in audience ratings and program availability, which increase at the end of the work day. By contrast, radio and print news get also accessed in the transition to and from work, in addition to the home space. Moreover, for newspapers in particular, news consumption increases during the weekend, especially on Sunday [9]. These temporal patterns are fairly stable but not fixed, since people availability affect them, in particular the amount of leisure time available [21].

Finally, a host of studies have shown how the practices of consuming news in print and broadcast media are intertwined within the interactional patterns of daily life [8], [11], [25], [34], [41], [42]. This applies to television viewing and family conversations [32], newspaper reading and workplace interactions [9], and sociability outside of the home and work environments [3], [28].

\subsection{News consumption in digital media}

The advent of news on bulletin boards and online services first, and then on the web, triggered the emergence of scholarly research aimed at understanding the dynamics of news consumption using computerized devices [35], [36]. Two lines of research are particularly relevant for present purposes: whether the advent of online news complements or displaces news consumption in print and broadcast media; and whether online news consumption alters the temporal and spatial coordinates of getting the news in those media.

Concerning the former, the scholarship has been divided into two opposing camps. One argues that the consumption of online news complements that of print and broadcast media [39], [40], [48], [51], [54]. The alternative camp suggests that there is a displacement effect whereby increased consumption of online news decreases time and attention devoted to news in print and broadcast media [17], [20], [22]. Of particular relevance to this paper, the research shows that 
displacement is greater among better educated and younger users [1], [13], [15], [16], [20].

Regarding the latter, the work of Boczkowski [5] on the consumption of online news at work shows patterns of both discontinuity and continuity with respect to the consumption of news at home in print and broadcast media. The research reveals two ideal typical forms of news consumption, a "first visit" which is habitualized, longer and usually earlier in the day, and "subsequent visits" that are not habitualized, much shorter in duration, and normally later in the day, and are centered on getting news updates during breaks from work. The "subsequent visits" are discontinuous from the highly routinized forms of news consumption in print and broadcast media. Patterns of news consumption at work show the continued importance of integrating this practice with broader interactional patterns since many times a person consumes news to talk about it with co-workers.

\subsection{Digital news consumption and social media}

Because the consumption of news on social media is a relatively recent phenomenon, research on it is still sparse. But there are two sets of issues emerging from the existing literature that inform the current paper. First is a general understanding of the dynamics of the phenomenon. Second is the notion that news on social media emerge from a novel set of practices called "ambient journalism".

Two findings from the handful of empirical studies currently available on news consumption in social media are particularly relevant for present purposes. First, Bucholtz [10] found that increased news consumption on social networking sites was tied to decreased news consumption on other media platforms, thus indirectly contributing towards a displacement effect. Second, Shim and colleagues [43] showed that use of mobile communication devices shapes news consumption on social media. This is supported by the conclusion from Choi's [12] study that greater number of mobile devices is correlated with more news being consumed on social media.

Hermida [27] argued that the growth of social media networks like Twitter led to the emergence of a new form of always-on and ubiquitous awareness system that he called "ambient journalism." His account focused on the production side of ambient journalism and made assumptions about the audience uptake and contributions to this new ecology of information. Empirical research on what actually users do when they engage with this new form of journalism has been sparse. Hermida [26] noted the potential of such research: "The extent to which such systems of ambient journalism allow citizens to maintain an awareness of the news events and the conversation around them would be a fertile area for future study". The present study aims to contribute towards this goal.

\section{Methodology}

This paper is based on sixteen open-ended interviews with young (ages 18-29) consumers of digital news in Argentina. The interviews were conducted face-to-face by a team of research assistants coordinated by the third author and supervised by the first two. All but one of the interviews took place in the city of Buenos Aires - the nation's capital-and surrounding towns between March and June, 2016; one of them was led in the city of Córdoba. Interviewees chose the location of the interviews, which lasted an average of 45 minutes and were tape-recorded and transcribed in their entirety.

Interviewees were recruited using a snowball sampling technique adapted to the team approach to data collection. That is, each research assistant invited a distant contact to be interviewed by another research assistant in the team. These contacts were diverse in terms of gender. At the end of the interview, each interviewee was requested names of three-to-five of their acquaintances and the interviewer requested permission to contact one or more of them for the purposes of this study. On a random basis, some of these acquaintances were approached and the others were placed on a waiting list. This procedure was repeated with each person who was subsequently interviewed. The final sample consisted of 5 men and 11 women, and had a mean age of 22.8 years-old. Based on their education level, which almost always included pursuing a college degree, participants belonged to upper or upper-middle socioeconomic strata of society.

Data analysis began after the first few interviews and continued in parallel with the data collection process. The data were analyzed in a grounded theory fashion. The authors read the transcripts, looking for recurring themes in an iterative fashion until a theoretical interpretation of the phenomena under study emerged and gradually solidified [44].

\section{Findings}

Drawing upon the texto-material perspective briefly outlined in the Introduction, in this section we first examine the key technological affordances in both hardware and software that are implicated in online 
news consumption in social media by youth. Then we look at the content practices associated with this mode of news consumption. As will become evident in the paragraphs that follow, users' agency weaves together these material and textual dimensions of media use.

\subsection{Material matters}

When we asked interviewees to rank their everyday use of screen devices, they almost invariably put mobile phones at the top, followed by computers and television sets. When we invited them to elaborate on their respective rankings, they usually noted that mobile phones were the most important screen device for them because they used them more often than any other device, and for a multiplicity of purposesincluding news consumption. By contrast, computers and television sets were used much less frequently and normally for a single-use purpose-instrumental goals such as work and study for the former, and entertainment for the latter. For instance, a 24-year-old female undergraduate student shared that "my mobile phone is what I use the most due to constant communication, with family, friends, [and] my boss. And then the computer. I use my computer a lot for college, and also for my job" [P6]. In a similar vein, a 22-year-old female undergraduate student said that "I use my computer almost exclusively for college stuff. My mobile phone would be for a general use" [P9].

The primacy of the mobile phone shapes news consumption among young people: the vast majority of them said that it is through this device that they access news stories on a regular basis. Furthermore, in most cases this consumption is somewhat seamlessly integrated with their use of social media. When they visit Facebook, primarily, and Twitter, secondarily, they encounter information about a news story and if it catches their attention, they often click on the link to find out more about the news. For instance, when asked about the most recent time he had learned about a news story, a 28-year-old male worker in the commercial sector said "the truth is that I was on Facebook and on my wall somebody shared a story, so I clicked on the link because it interested me... It was casual [news consumption] because that topic interested me in particular. Otherwise, I do not normally visit the sites of digital newspapers or things like that" [P2]. Another interviewee shared a similar practice, but also noted a certain spillover effect whereby an incidental visit to a news site might lead to more time spent looking at its content: "In general I go [to a news site] through Facebook because somebody shared an article... And then I look at the other headlines and if there is one that catches my eye, I click on the story" [P9].
To further understand the dynamics of incidental news consumption it is worth noticing that most of our interviewees do not see themselves as using social media but as living in them, as a digital environment that is akin to the urban and natural environments that envelop their daily lives. A 19-year-old college student put it as follows: "For two months I stopped using Facebook. But then I realized that it was hard... One always wants to fight against the system, but you can't live outside of it" [P16]. Another college student says she is on social media "All the time. I grab my cell phone and [look at them] all the time" [P15]. A 29year-old male worker in film production commented that "you have to use [Facebook] because today it is the way that you have to communicate" [P5].

Thus, in the same way that a person might run into a forgotten acquaintance on the street or see a beautiful bird while running in the park, our interviewees encounter news while they spend their time living in social media. For instance, a 19-year-old female undergraduate student said that "I use Facebook every day... Since I have a mobile phone, access [to Facebook] is very easy, so you have a second to spare and you look and find out information" [P3]. This derivative character of news consumption on social media is further reinforced by the algorithmic logic of Facebook and the chronological logic of Twitter, which add to erase the difference between a news story produced by a media company and the posts about funny kittens or vacation photos contributed by regular users connected through Facebook and Twitter. The worker in the commercial sector told the interviewer that "I read what others share on Facebook because it is now like a mass of information, or disinformation, and there is a lot [of it] so I look at it quite a bit" [P8].

The combination of living in social media (instead of using it more purposely and sporadically, as in the case of print or broadcast media) and consuming news incidentally on it (as opposed to doing it as a deliberate and discreet habit) turns media frenzies into more effective ways of capturing the attention of the young population than what was the case with traditional media. Viralization via Facebook sharing or Twitter trending appears to make the public's attention rapidly coalesce. A 27-year-old female media producer explained that she has two "mechanisms" that drive which stories she reads: "One is because I have an a priori interest... The other is because I see [a story] replicated many times, usually on Facebook" [P10]. A 21-year-old female college graduate shared a similar mechanism, in her case on Twitter: "I read the news story about the person who killed someone in the business district because I saw that 'business district' was a trending topic and so I wanted to see what's going on" [P1]. 


\subsection{Content practices}

The incidental news consumption on social media is linked to acquiring information multiple times a day, in an unroutinized fashion, spending very short periods of time doing it, and reading the content partially. A 20-year-old female undergraduate student said that "I read a story as I get into her car, then stop while I travel, and when I get to college while I enter through the building [where she has class] and read another story" [P7]. Another interviewee, a 20-year-old female college student, noted that "it isn't that I have a set amount of time that I devote [to news consumption]... some days I don't read anything and others I read everything that shows up [on my social media feeds]" [P4].

When they look at a story, most interviewees describe a very superficial reading of the texts. A 22year-old female college student commented, "I read the headline, the lead and then skim-read the content [of the article]" [P9]. Another interviewee concurred: "I do a scan of headlines, and if there is anything that interests me a lot, then I click [on the story]" [P10]. In some cases, these content practices elicit feelings of guilt: "the truth is that I should read more [the news]", [P3] and "I don't want to get to my job and realize that something happened and I didn't know" [P8]. But these feelings of guilt do not seem to be powerful enough to effect a change of practices.

It is worth comparing these content practices associated with incidental news consumption with those that prevail in the case of the consumption of entertainment. In this latter case, our interviewees refer to a suite of practices that takes place in relation to the television or computer screen; appear to be intentional and fairly differentiated-even in the presence of the second screen phenomenon, focus primarily on the material on the screen; and is longer in duration than in case of news. For instance, a 20-year-old female college student said that "if I have time to sit down and watch a movie or a television show, I go to the TV, or otherwise on the computer" [P4]. As the previous participant noted, devoting significant time to consuming entertainment implies some degree of scheduling. This seems to be related to a connection between consuming entertainment content and pleasure that is absent in the case of news: "the moment of saying, 'hey, how about if we see a chapter of this [television show]?' is very enjoyable. It doesn't have to do with everyday routines or anything like that, but with something [enjoyable] that we allow ourselves [to experience]" [P10].

\section{Discussion}

The interviews with sixteen young users of digital media reveal that news consumption on social media can be captured with the label of "incidental news". They encounter news items, rather than actively looking for them, as part of their constant connection through social media, often through their mobile devices. This mode of access un-differentiates news from other types of information content, such as postings from friends and family on social media feeds. It also is tied to a low degree of attention to journalistic information: young users click on news items sporadically, if at all, and engage with them only superficially on most occasions.

The incidental mode of news consumption on social media runs counter to the findings about high routinization of news consumption on print, broadcast, and to a somewhat lesser extent, on the web. There was no trace of stable temporal and spatial patterns in news access among the subjects of this study, little predictability either for themselves or for content producers. Boczkowski [5] examined the transition of news consumption on print and broadcast at the home space and at leisure time to the web, at the time and place of work. This transition included the combination of a first visit, relatively long, planned, highly habitualized - akin to the routinization of print and broadcast news consumption at home-with subsequent, shorter visits to news sites to get updates during brief and mostly unplanned breaks at work. Incidental news access resonates with these subsequent visits, without the grounding of the first visit. Moreover, the location of accessing news content has moved from home and work to everywhere and nowhere in particular at the same time. News consumption on social media via mobile devices is no longer structured along the ebbs and flows of the workday, but rather interspersed throughout the day without the predictability that characterized access to news in print newspapers, radio, television, and computers.

The analysis of incidental news strengthens the centrality of the integration of media consumption with the social interactions in daily life, but puts a new spin on it. For the participants, sociability is not only facilitated by using media and news as social currency, exchanged at the water cooler at work or social events; it is also conducted within social media, seamlessly integrating information from friends, co-workers and family with editorial content curated by a combination of friendship networks and the algorithms of social media platforms. That is, consumers are presented with news items in part because their friends post about them but also in part because social media and news 
companies push that content. Connection between media and sociability is furthered by social contacts sharing news items and posting comments about them, all through the same mobile device, permanently in the hands or the pockets of participants. Our interviewees show the extent to which news and sociability are always just a swipe away, un-differentiated and inextricably linked on social media.

The centrality of news consumption on social media signals what might become a definitive turn from the complementarity of time spent consuming news between print and broadcast media with online news, to digital sources displacing "old" mediaparticularly among young audiences. The mobile device has become the main connection with the world of information, while television appears to be relegated mostly for entertainment, and the computer for work and study purposes. Print artifacts seem almost entirely absent from young people's news repertoire. This constant, low-grade level of awareness of news illustrates how the concept of ambient journalism hypothesized by Hermida [26] works on the ground, and points to a radically new ecology of information. In this new environment, the cost of getting audiences' sustained attention is raised for routine news - which is most of the news that is produced and consumed-but might be dramatically lowered for events triggering media frenzies, thus putting a new spin on the normative model of journalism sounding burglar alarms when important events for the polity take place [55]. This new ecology of information also lowers the bar for sharing and commenting on everyday life events, although these events might not necessarily be the most newsworthy in the old media environment, of highly routinized and bureaucratically focused news.

The increasing prevalence of what we have described as "incidental news" consumption on social media among youth creates several challenges for professional content producers, two of which we would like to highlight. The first one is the demise of a privileged place of news in the informational hierarchy, which is in turn linked to news organizations losing their agenda-setting power [4], [7], [46]. The weakening of agenda-setting is compounded with the de-intermediation effects of users following politicians, sports stars, show-business personalities and other news makers directly on social networks. It is also compounded by the re-intermediation consequences of respondents accessing news content through the recommendation-shares or retweets - of friends, family or other social media contacts, in a reversioning of the two-step flow process proposed by Katz and Lazarsfeld [29] more than sixty years ago.

\section{Conclusion}

In this paper we have examined the consumption of news in social media among youth. Our account shows the emergence of a novel ideal-typical mode of news consumption that what we have called "incidental news" and that has become the dominant mode of information acquisition for this segment of the population: news content encountered on mobile devices while visiting social media sites, in a process that is derivative of social media interactions rather than deliberately sought for-as opposed to the consumption of entertainment content on television. In this novel mode of news consumption young consumers are surrounded by news content that is undifferentiated from other types of content on their social media feeds. They are exposed to them constantly but clicked on sporadically and very little time is devoted to reading or watching the stories. We have argued that the emergence of incidental news signals a major discontinuity with the information ecologies associated with the consumption of news on print and broadcast media - and, to a lesser extent, with the consumption on news sites via laptop or desktop computers - and elaborated on its key editorial and political implications.

\section{References}

[1] Althaus, S. L., Cizmar, A. M., and Gimpel, J. G, "Media Supply, Audience Demand, and the Geography of News Consumption in the United States", Political Communication, 26(3), 2009, pp. 249 - 277.

[2] Barnhurst, K.G. and Wartella, E., "Young citizens, American TV newscasts and the collective memory", Critical Studies in Media Communication, 15(3), 1998, pp. 279-305.

[3] Bausinger, H., "Media, technology and daily life", Media Culture \& Society, 6(4), 1984, pp. 343-351.

[4] Bennett, W. L., and Iyengar, S., "A new era of minimal effects? The changing foundations of political communication", Journal of Communication, 58(4), 2008, pp. 707-731.

[5] Boczkowski, P. J., News at work: Imitation in an age of information abundance, University Of Chicago Press, Chicago, 2010.

[6] Boczkowski, P. and Lievrouw, L. A., "37 Bridging STS and Communication Studies: Scholarship on Media and Information Technologies", The handbook of science and technology studies, 2008, p. 949. 
[7] Boczkowski, P. J., and Mitchelstein, E., The news gap: When the information preferences of the media and the public diverge, MIT Press, Cambridge, Massachusetts, 2013.

[8] Bogart, L., "Adult conversation about newspaper comics", American Journal of Sociology, 61, 1955, pp. 2630 .

[9] Bogart, L., Press and Public: Who Reads What, When, Where, and Why in American Newspapers, Lawrence Erlbaum, Hillsdale, NJ, 1989.

[10] Bucholtz, I., "Media Use Among Social Networking Site Users in Latvia", International Journal of Communication, 9, 2015, pp. 2653-2673.

[11] Chan, T. W., and Goldthorpe, J. H., "Social status and newspaper readership", American Journal of Sociology, 112(4), 2007, pp. 1095-1134.

[12] Choi, J., "Why do people use news differently on SNSs? An investigation of the role of motivations, media repertoires, and technology cluster on citizens' news-related activities", Computers in Human Behavior, 54, 2016, pp. 249-256.

[13] Coleman, R., and McCombs, M. "The young and agenda-less? Exploring age-related differences in agenda setting on the youngest generation, baby boomers and the civic generation", Journalism \& Mass Communication Quarterly, 84(3), 2007, pp. 495-508.

[14] Dayan, D., and Katz, E., Media Events: The Live Broadcasting of History, Harvard University Press, Cambridge, MA, 1992.

[15] De Waal, E., and Schoenbach, K. "News sites' position in the mediascape: uses, evaluations and media displacement effects over time", New Media \& Society, 12(3), 2010, pp. 477-497.

[16] Diddi, A., and LaRose, R., "Getting Hooked on News: Uses and Gratifications and the Formation of News Habits Among College Students in an Internet Environment", Journal of Broadcasting \& Electronic Media, 50(2), 2006, pp. 193-210.

[17] Dimmick, J., Chen, Y., and Li, Z., "Competition between the Internet and traditional news media: The gratification-opportunities niche dimension", Journal of Media Economics, 17(1), 2004, pp. 19-33.

[18] Downs, A. An economic theory of democracy, Harper, New York, 1957.

[19] Gans, H. J., Democracy and the News, Oxford University Press, New York, 2004.

[20] Gaskins, B., and Jerit, J., "Internet News: Is It a Replacement for Traditional Media Outlets?", International Journal of Press-Politics, 17(2), 2012, pp. 190-213.
[21] Gauntlett, D., and Hill, A., TV Living: Television, Culture and Everyday Life, Routledge, New York, 1999.

[22] Gentzkow, M., "Valuing new goods in a model with complementarity: Online newspapers", American Economic Review, 97(3), 2007, pp. 713-744.

[23] Gillespie, T., Boczkowski, P. J. and Foot K. A., Media technologies: Essays on communication, materiality, and society, MIT Press, Cambridge, Massachusetts, 2014.

[24] Gottfried, J., and Shearer, E, "News Use Across Social Media Platforms", Pew Research Center, Washington, DC, 2016.

[25] Graber, D., Processing the News: How People Tame the Information Tide, Longman, White Plains, NY, 1984.

[26] Hermida, A., "Twittering the News: The Emergence of Ambient Journalism", Journalism Practice, 4(3), 2010, pp. 297-308.

[27] Hermida, A. Tell everyone: Why we share and why it matters. Doubleday Canada, 2014.

[28] Jensen, K. B., "The politics of polysemy: Television news, everyday consciousness and political action", Media, Culture \& Society, 12(1), 1990, pp. 57-77.

[29] Lazarsfeld, P. F., and Katz, E., Personal influence: the part played by people in the flow of mass communications, Glencoe, Illinois, 1955.

[30] Lee, J., Incidental exposure to news: limiting fragmentation in the new media environment (Unpublished doctoral dissertation), University of Texas at Austin, 2008.

[31] Luhmann, N., The reality of the mass media, Stanford University Press, Stanford, California, 2000.

[32] Lull, J., "The social uses of television", Human Communication Research, 6(3), 1980, pp. 197-209.

[33] Lull, J., "How families select television programs: A mass-observational study", Journal of Broadcasting \& Electronic Media, 26(4), 1982, pp. 801-11.

[34] Martin, V. B., "Attending the news: A grounded theory about a daily regimen”, Journalism, 9(1), 2008, pp. 76-94.

[35] Mitchelstein, E., and Boczkowski, P. J., "Online News Consumption Research: An Assessment of Past Work and an Agenda for the Future", New Media \& Society, 12(7), 2010, pp. 1085-1102.

[36] Mitchelstein, E., and Boczkowski, P. J., "Tradition and transformation in online news production and consumption", The Oxford Handbook of Internet Studies, 2013, p. 378. 
[37] Morley, D, "The nationwide audience: Structure and decoding”, British Film Institute, 11, London, 1980.

[38] Morley, D, and Lull, J., "Domestic relations: the framework of family viewing in Great Britain", World families watch television, 1988, pp. 22-48.

[39] Newell, J., Pilotta, J., and Thomas, J., "Mass Media Displacement and Saturation", International Journal on Media Management, 10(4), 2008, pp. 131-138.

[40] Nguyen, A., and Western, M., "The complementary relationship between the Internet and traditional mass media: the case of online news and information", Information Research-an International Electronic Journal, 11(3), 2006.

[41] Palmgreen, P., Wenner, L., and Rayburn II, J. D., "Relations between gratifications sought and obtained: A study of television news", Communication Research, 7(2), 1980, pp. 161-92.

[42] Robinson, J. P., and Levy, M., "Interpersonal communication and news comprehension", Public Opinion Quarterly, 50(2), 1986, pp. 160-75.

[43] Shim, H., You, K. H., Lee, J. K., and Go, E., "Why do people access news with mobile devices? Exploring the role of suitability perception and motives on mobile news use", Telematics and Informatics, 32(1), 2015, 108-117.

[44] Siles, I., and Boczkowski, P. J., "At the Intersection of Content and Materiality: A Texto-Material Perspective on the Use of Media Technologies", Communication Theory, 22, 227-249, 2012

[45] Silverstone, R., Television and Everyday Life Research, Routledge, London, 1994.

[46] Singer, J. B. "User-generated Visibility: Secondary gatekeeping in a shared media space", New Media \& Society 16(1), 2014, pp. 55-73.

[47] Strauss, A., and Corbin, J., Basics of qualitative research, Sage, Newbury Park, CA, 1990.

[48] Taneja, H., Webster, J. G., Malthouse, E. C., and Ksiazek, T. B., "Media consumption across platforms: Identifying user-defined repertoires", New Media \& Society, 14(6), 2012, pp. 951-968.

[49] Tewksbury, D. H., Weaver, A. J., and Maddex, B. D., "Accidentally informed: Incidental news exposure on the World Wide Web", Journalism \& Mass Communication Quarterly, 78(3), 2001, pp. 533-554.

[50] Thompson, J. B., The media and modernity: A social theory of the media, Stanford University Press, Stanford, CA, 1995.
[51] Van der Wurff, R., “Are News Media Substitutes? Gratifications, Contents, and Uses", Journal of Media Economics, 24(3), 2011, pp. 139-157.

[52] Von Hippel, E., "Lead users: a source of novel product concepts", Management science, 32(7), 1986, pp. 791-805.

[53] Webster, J., and Phalen, P., The Mass Audience: Rediscovering the Dominant Model, Lawrence Erlbaum, Mawhaw, NJ, 1997.

[54] Yuan, E., "News consumption across multiple media platforms: A repertoire approach", Information Communication \& Society, 14(7), 2011, pp. 998-1016.

[55] Zaller, J., "Monica Lewinsky's contribution to political science", PS: Political Science \& Politics, 31(2), 1998, pp. 182-189. 